Article

\title{
Evaluation of the Adsorption Performance and Sustainability of Exfoliated Graphite Nanoplatelets (xGnP) for VOCs
}

\author{
Seong Jin Chang, Seunghwan Wi, Su-Gwang Jeong and Sumin Kim * \\ Received: 9 September 2015 ; Accepted: 4 November 2015 ; Published: 11 November 2015 \\ Academic Editor: Changle Chen \\ School of Architecture, Soongsil University, Seoul 156-743, Korea; tjdwls329@ssu.ac.kr (S.J.C.); \\ dnltmdghks@ssu.ac.kr (S.W.); wjdtnrhkd@ssu.ac.kr (S.-G.J.) \\ * Correspondence: skim@ssu.ac.kr; Tel.: +82-2-820-0665; Fax: +82-2-816-3354
}

\begin{abstract}
Exfoliated graphite nanoplatelets $(\mathrm{xGnP})$, which combine the layered structure and low price of nanoclays with the superior mechanical, electrical, and thermal properties of carbon nanotubes, are very cost-effective, and can simultaneously provide a multitude of physical and chemical property enhancements. In this study, we evaluated $x \mathrm{GnP}^{\prime} \mathrm{s}$ adsorption performance of volatile organic compounds (VOCs) according to thermal extractor (TE) analysis for seven days in order to use the $\mathrm{xGnP}$ as an adsorption material of pollutants. In addition, we carried out a sustainability evaluation in order to evaluate its adsorption capacity over 28 days. The results indicate that the adsorption performance of $\mathrm{xGnP}$ is higher than for other adsorption materials such as zeolite. Also, we determined that the adsorption performance of $x \mathrm{GnP}$ is maintained continuously for 28 days and that its adsorption capacity is large.
\end{abstract}

Keywords: volatile organic compounds (VOCs); exfoliated graphite nanoplatelets (xGnP); adsorption performance; thermal extractor analysis; indoor air quality

\section{Introduction}

Among all pollutants, building materials play a major role in determining the indoor air quality due to their large surface area and permanent exposure to indoor air. Building materials can release a wide range of pollutants, particularly volatile organic compounds (VOCs), which can degrade indoor air quality, making it worse than that of outdoor air [1]. Recent studies of VOC emissions in four newly built, unoccupied test houses showed that the building materials are the main source of indoor air pollution [2]. Polymeric materials that emit a lot of VOCs are used widely in the construction, decorating, and furnishing of homes, offices, and schools, as well as other non-industrial work places. Some constitute large surface areas within buildings, such as coatings and coverings on walls, ceilings, and floors [3]. VOCs are often noxious or carcinogenic, either directly or indirectly, posing many severe environmental problems such as adverse effects on human health at very low concentrations [4]. Various studies have proposed some common methods for the removal of VOCs, including thermal oxidation, adsorption, condensation, membrane separation, and biological treatment [5-10]. Among these methods, adsorption has been proven to be an effective method for the removal of VOCs because it is fast, safe, and economically feasible [5].

Inorganic and natural materials can be used for the adsorption of VOCs. Zeolites and activated carbons, which are inorganic materials, are the most commonly used for the adsorption of VOCs and are an effective means of collecting these harmful compounds [11]. These adsorption materials of VOCs are substantially porous, and graphite is also a porous carbon material and its specific surface area and pore volume can be expanded by using the shape modification process [1]. Recently, studies 
examining exfoliated graphite nanoplatelets have been conducted, and Thostenson et al. carried out research for the ultrasonicated-ozone modification of exfoliated graphite (EG) [12]. Exfoliated graphite nanoplatelets $(\mathrm{xGnP})$ are comprised of a graphitic carbon-based material. $\mathrm{xGnP}$ that are less than $10 \mathrm{~nm}$ thick and have a diameter of $15 \mu \mathrm{m}$ are made through acid treatment, blasting, and shredding processes $[13,14]$. Most of the adsorption materials such as zeolite, diatomite, and active carbon have already been evaluated, but not $\mathrm{xGnP}$. The measurement method for evaluating the adsorption of VOCs is done according to ISO/DIS 16000-23, ISO/DIS 16000-24, JIS A 1905-1, JIS A 1905-2, JIS A 1906 [15-20]. The adsorption ratio after seven days and the cumulative adsorption amount over seven days is measured. The methods also measure the re-emission for three days. The adsorption performance of the adsorbent material is evaluated by the foregoing measurement results. However, because of differences in the adsorption capacities of adsorption materials, a long-term performance evaluation is necessary.

In this study, we evaluated the adsorption performance of $x \mathrm{GnP}$ and other adsorption materials using thermal extractor analysis for seven days. In addition, we conducted a sustainability evaluation in order to evaluate the adsorption capacity of the adsorption materials for 28 days.

\section{Experimental Section}

\subsection{Materials}

xGnP was prepared from sulphuric acid-intercalated expandable graphite (3772) (obtained from Asbury Graphite Mills, NJ, USA), by applying a cost- and time-effective exfoliation process that was initially proposed by Drzal's group. $x \mathrm{GnP}$, which combines the layered structure and low price of nanoclays with the superior mechanical, electrical, and thermal properties of carbon nanotubes, is very cost-effective, and can simultaneously provide a multitude of physical and chemical property enhancements [21,22]. Zeolite and perlite are porous materials and offer excellent adsorption performance of the pollutants. In this study, they are used for comparison with $\mathrm{xGnP}$, and both natural and improved zeolites (JST-MS100, Daejin Chemical, Namyang-Ju, Korea) were used. Table 1 sets out the specific surface area $\left(\mathrm{m}^{2} \cdot \mathrm{g}^{-1}\right)$ and total pore volume $\left(\mathrm{cm}^{3} \cdot \mathrm{g}^{-1}\right)$ of the four samples by Brunauer Emmett Teller (BET) analysis, and Figure 1 shows the Scanning electron microscop (SEM) images of $x \mathrm{GnP}$.

Table 1. The result of Brunauer Emmett Teller (BET) analysis.

\begin{tabular}{ccc}
\hline Samples & Specific Surface Area $\left(\mathbf{m}^{2} \cdot \mathbf{g}^{-1}\right)$ & Total Pore Volume $\left(\mathrm{cm}^{3} \cdot \mathbf{g}^{-1}\right)$ \\
\hline xGnP & 20.4 & 0.082 \\
Perlite & 3.3 & 0.004 \\
Zeolite (Natural) & 23.4 & 0.031 \\
Zeolite (JST-MS100) & 755.6 & 0.352 \\
\hline
\end{tabular}

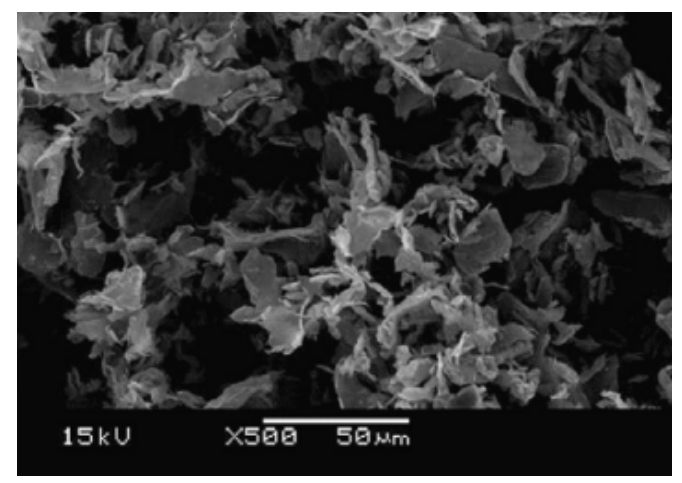

Figure 1. Scanning electron microscop (SEM) images of Exfoliated graphite nanoplatelets (xGnP). 


\subsection{Methods}

\subsubsection{Thermal Extractor (TE)}

The seven-day evaluation and the sustainability evaluation were conducted through thermal extractor (TE) analysis. TE analysis is used mainly to measure the total VOC (TVOC) and formaldehyde emitted from construction materials such as medium density fiberboard (MDF), particle board (PB), paints, and adhesives. TE analysis can be used with very small samples to measure pollutant emissions, and the test can be run according to temperature because the samples can raise the temperature by $190{ }^{\circ} \mathrm{C}$. The test samples were conditioned before testing at $50 \% \pm 5 \%$ relative humidity (RH) for at least $24 \mathrm{~h}$ and sealed in aluminum foil [1].

Figure 2 shows a schematic diagram of the thermal extractor (TE). The TE consists of an adjustable oven heating a glass tube with a sample inside. Adsorbed samples were placed in a glass extraction tube. The adsorbed sample size was limited, both by the diameter of the tube and by the heatable length of the oven, to a maximum of $70 \mathrm{~mm}$. The VOCs were purged under a pure nitrogen gas stream at a constant flow on a Tenax TA tube and 2,4-DNPH (dinitrophenylhydrazine) cartridge; 2,4-DNPH, followed by high performance liquid chromatography (HPLC) analysis, is a widely used selective and sensitive method for the measurement of carbonyl compounds in air. In normal use, the entire gas flow passes over the adsorbent material. The sampling volume was $1 \mathrm{~L}$ [1,23]. The VOC concentrations were analyzed by using GC-MSD. GC-MSD is a gas chromatography (GC, Agilent-6890N, National Instrumentation Center for Environmental Management, Seoul, Korea)-mass spectrum detector (MSD, Agilent-5975, National Instrumentation Center for Environmental Management).

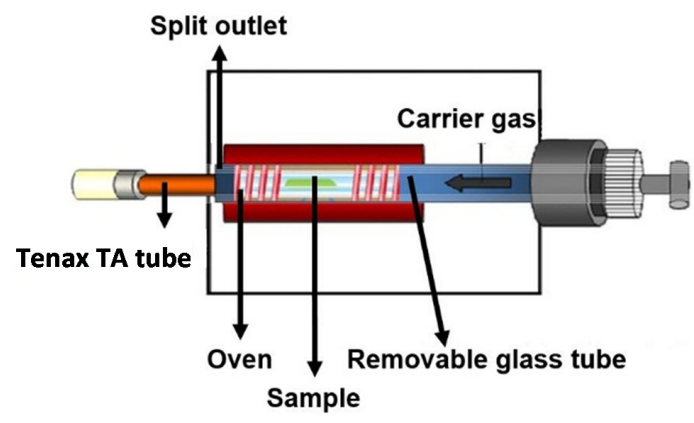

Figure 2. Schematic diagram of the thermal extractor (TE).

\subsubsection{Evaluation of Adsorption Performance}

We conducted a comparative experiment with $x \mathrm{GnP}$, zeolite, and perlite. The comparative experiment is a simple experiment, other than the method specified in ISO/DIS 16000-23, ISO/DIS 16000-24, JIS A 1905-1, JIS A 1905-2, JIS A 1906, used in order to evaluate only the adsorption performance of $x \mathrm{GnP}$. First, $10 \mathrm{~g}$ samples of $\mathrm{xGnP}$, zeolite (both natural and JST-MS100), and perlite were prepared. The prepared samples were placed in a constant temperature and humidity chamber that was maintained at $25^{\circ} \mathrm{C}$ and $50 \%$ humidity, respectively. Then, a source emitting VOCs was introduced to the chamber at 24-h intervals. After seven days, the pollutants adsorbed on each sample were analyzed by thermal extractor (TE) analysis. Additionally, a sustainability evaluation was conducted for 28 days under the same conditions.

\section{Results and Discussion}

\subsection{Adsorption Performances of the Samples over Seven Days}

This experiment can be compared to the adsorption performance in the same experimental conditions. Table 2 shows the adsorption performances of the samples over seven days. After 
seven days, the TVOC adsorption amount of perlite was $150.48 \mu \mathrm{g} / \mathrm{m}^{3}$, which was the highest amount among the four samples. Next, the TVOC adsorption amount of $x \mathrm{GnP}$ was $128.93 \mu \mathrm{g} / \mathrm{m}^{3}$. The lowest TVOC adsorption amount was that of natural zeolite, at $9.99 \mu \mathrm{g} / \mathrm{m}^{3}$. This value indicates that the TVOC adsorption ability of $\mathrm{xGnP}$ is 12.91 times larger than that of natural zeolite. The 5VOC (benzene, toluene, ethyl benzene, xylene, styrene) adsorption amount of $\mathrm{xGnP}$ was $25.08 \mu \mathrm{g} / \mathrm{m}^{3}$. Although the TVOC adsorption amount of $\mathrm{xGnP}$ was not the highest, its 5VOC adsorption amount was the highest. Although the experimental conditions were not based on international standards, this result indicates that the adsorption performance of $\mathrm{xGnP}$ is higher than that of existing adsorption materials.

Table 2. Result of adsorption performance for seven days.

\begin{tabular}{ccccc}
\hline Samples & Zeolite (JST-MS100) & Zeolite (Natural) & Perlite & xGnP \\
\hline TVOC $\left(\mu \mathrm{g} / \mathrm{m}^{3}\right)$ & 76.91 & 9.99 & 150.48 & 128.93 \\
Benzene $\left(\mu \mathrm{g} / \mathrm{m}^{3}\right)$ & 2.17 & 1.71 & 2.69 & 4.37 \\
Toluene $\left(\mu \mathrm{g} / \mathrm{m}^{3}\right)$ & 2.07 & 1.61 & 10.38 & 18.83 \\
Ethyl Benzene $\left(\mu \mathrm{g} / \mathrm{m}^{3}\right)$ & - & - & - & - \\
Xylene $\left(\mu \mathrm{g} / \mathrm{m}^{3}\right)$ & - & - & - & 1.89 \\
Styrene $\left(\mu \mathrm{g} / \mathrm{m}^{3}\right)$ & - & - & - & - \\
5VOC $\left(\mu \mathrm{g} / \mathrm{m}^{3}\right)$ & 4.25 & 3.33 & 13.07 & 25.08 \\
5VOC $(\%)$ & 5.52 & 33.13 & 8.69 & 19.45 \\
\hline
\end{tabular}

\subsection{Sustainability Evaluation for 28 Days}

Figure 3 and Table 3 show the sustainability of the samples' adsorption performance. As previously mentioned, the TVOC adsorption amount of perlite was the highest after seven days, with $\mathrm{xGnP}$ the next highest. However, during the second week, the TVOC adsorption amount of $\mathrm{xGnP}$ increased from 128.93 to $1545.31 \mu \mathrm{g} / \mathrm{m}^{3}$ on the 14th day. This was the highest adsorption amount among the four samples on the 14th day. In addition, $\mathrm{xGnP}^{\prime} \mathrm{s}$ adsorption of xylene increased by $153 \%$ during the second week. Figure 4 shows the xylene adsorption performance of $x G n P$. On the other hand, perlite, which showed the highest performance at seven days, was reduced from 150.48 to $101.95 \mu \mathrm{g} / \mathrm{m}^{3}$ on the 14th day. Over the entire sustainability evaluation period of 28 days, the TVOC adsorption amount of zeolite (JST-MS100) increased from $86.96 \mu \mathrm{g} / \mathrm{m}^{3}$ at seven days to $105.50 \mu \mathrm{g} / \mathrm{m}^{3}$ on the 14th day, and then fell back to $72.49 \mu \mathrm{g} / \mathrm{m}^{3}$ on the 28th day. Natural zeolite and perlite were decreased continuously from seven to 28 days. The TVOC adsorption amount of $x G n P$ only tended to increase steadily. This result shows that $\mathrm{xGnP}$ is more advantageous than existing adsorption materials over this longer period of time.

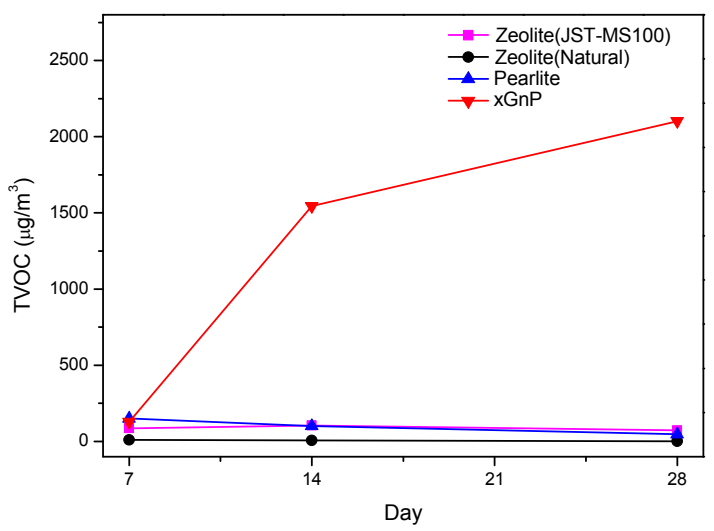

Figure 3. TVOC adsorption amount of $x \mathrm{GnP}$ for 28 days. 


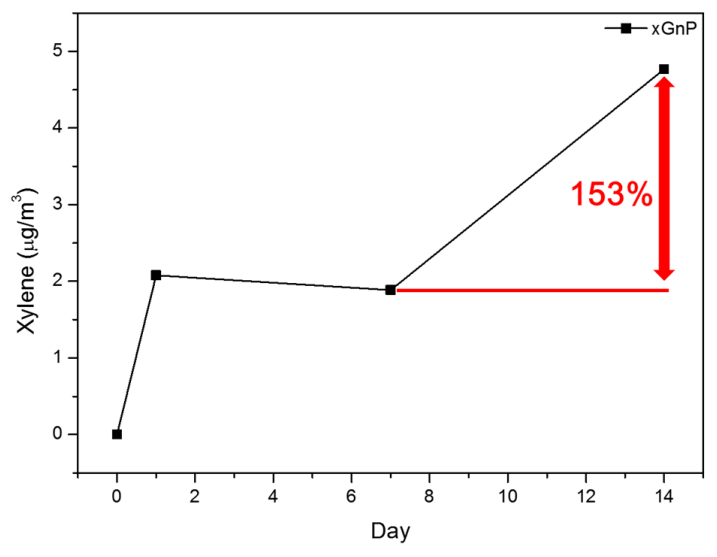

Figure 4. Xylene adsorption amount of xGnP.

Table 3. Sustainability evaluation of adsorption performance.

\begin{tabular}{cccc}
\hline TVOC & 7 days $\left(\mu \mathbf{g} / \mathbf{m}^{\mathbf{3}}\right)$ & $\mathbf{1 4}$ days $\left(\mu \mathbf{g} / \mathbf{m}^{\mathbf{3}}\right)$ & $\mathbf{2 8}$ days $\left(\mu \mathbf{g} / \mathbf{m}^{\mathbf{3}}\right)$ \\
\hline Zeolite (JST-MS100) & 86.96 & 105.50 & 72.49 \\
Zeolite (Natural) & 9.99 & 7.09 & 2.27 \\
Perlite & 150.48 & 101.95 & 48.20 \\
xGnP & 128.93 & 1545.31 & 2102.64 \\
\hline
\end{tabular}

\section{Conclusions}

In this study, we evaluated the adsorption performance of $x G n P$ for seven days. In addition, we carried out a sustainability evaluation in order to evaluate its adsorption capacity for 28 days.

On the basis of the obtained results, we concluded that the 5VOC adsorption amount of the $\mathrm{xGnP}$ showed the highest performance. Although our experimental conditions were not based on international standards, this result indicates that the adsorption performance of $\mathrm{xGnP}$ is higher than those of existing adsorption materials such as zeolite. Furthermore, the result of the sustainability evaluation was that the TVOC adsorption amount of $\mathrm{xGnP}$ only tended to increase steadily for 28 days. In other words, we determined that the adsorption performance of $\mathrm{xGnP}$ is maintained continuously and that its adsorption capacity is large. This result indicates that it is possible to discover promising new materials which are not necessarily highlighted during a seven-day evaluation. Therefore, it is necessary to consider new experimental methods for sustainability evaluations of adsorption performance.

We will later evaluate the TVOC adsorption performance of $x \mathrm{GnP}$ according to ISO/DIS 16000-23, ISO/DIS 16000-24, JIS A 1905-1, JIS A 1905-2, JIS A 1906, and we will study new experimental methods for sustainability evaluations of adsorption performance.

Acknowledgments: This research was supported by a grant (15RERP-B082204-02) from Residential Environment Research Program funded by Ministry of Land, Infrastructure and Transport of Korean government.

Author Contributions: Seong Jin Chang, Seunghwan Wi and Su-Gwang Jeong designed and conducted the experiment. Sumin Kim designed the project. All authors contributed to the analysis and conclusion.

Conflicts of Interest: The authors declare no conflict of interest.

\section{References}

1. Lee, J.H.; Kim, S. The determination of the adsorption performance of graphite for VOCs and formaldehyde. Energy Build. 2012, 46, 56-61. [CrossRef]

2. Yu, C.; Crump, D. A review of the emission of VOCs from polymeric materials used in buildings. Build. Environ. 1998, 33, 357-374. [CrossRef] 
3. Choi, D.H.; Kang, D.H.; Kim, S.S.; Yeo, M.S.; Kim, K.W. The impact of a non-adhesive floating installation method on emissions and indoor concentrations of VOCs. Indoor Built. Environ. 2010, 19, 435-443. [CrossRef]

4. Qu, F.; Zhu, L.; Yang, K. Adsorbtion behaviors of volatile organic compounds (VOCs) on porous clay heterostructures (PCH). J. Hazard. Mater. 2009, 170, 7-12. [CrossRef] [PubMed]

5. Hsu, L.J.; Lin, C.C. Binary VOCs absorption in a rotating packed bed with blade packings. J. Environ. Manag. 2012, 98, 175-182. [CrossRef] [PubMed]

6. Lalanne, F.; Malhautier, L.; Roux, J.C.; Fanlo, J.L. Absorption of a mixture of volatile organic compounds (VOCs) in aqueous solutions of soluble cutting oil. Bioresour. Technol. 2008, 99, 1699-1707. [CrossRef] [PubMed]

7. Heymes, F.; Demoustier, P.M.; Charbit, F.; Fanlo, J.L.; Moulin, P. A new efficient absorption liquid to treat exhaust air loaded with toluene. Chem. Eng. J. 2006, 115, 225-231. [CrossRef]

8. Dwivedi, P.; Gaur, V.; Sharma, A.; Verma, N. Comparative study of removal of volatile organic compounds by cryogenic condensation and adsorption by activated carbon fiber. Sep. Purif. Technol. 2004, 39, $23-37$. [CrossRef]

9. Ji, W.; Sikdar, S.K.; Hwang, S.T. Modeling of multicomponent pervaporation for removal of volatile organic compounds from water. J. Membr. Sci. 1994, 93, 1-19. [CrossRef]

10. Daubert, I.; Lafforgue, C.; Maranges, C.; Fonade, C. Feasibility study of a compact process for biological treatment of highly soluble VOCs polluted gaseous effluent. Biotechnol. Prog. 2001, 17, 1084-1092. [CrossRef] [PubMed]

11. Kim, K.J.; Ahn, H.G. The effect of pore structure of zeolite on the adsorption of VOCs and their desorption properties by microwave heating. Microporous Mesoporous Mater. 2012, 152, 78-83. [CrossRef]

12. Rider, A.N.; An, Q.; Thostenson, E.T.; Brack, N. Ultrasonicated-ozone modification of exfoliated graphite for stable aqueous graphitic nanoplatelet dispersions. Nanotechnology 2014, 25, 495607. [CrossRef] [PubMed]

13. Kim, S.; Do, I.; Drzal, L.T. Multifunctional exfoliated graphite nanoplatelets-LLDPE nanocomposites fabricated by solution compounding method and various screw rotating systems. Macromol. Mater. Eng. 2009, 294, 196-205. [CrossRef]

14. Kalaitzidou, K.; Fukushima, H.; Drzal, L.T. Mechanical properties and morphological characterization of exfoliated graphite-polypropylene nanocomposites. Compos. Part A Appl. Sci. Manuf. 2007, 38, 1675-1682. [CrossRef]

15. Kim, J.H.; Kim, H.J.; Yoon, D.W. Evaluation studies on the adsorption VOCs performance of the natural porous materials for the development of absorptive building materials. J. KIAEBS 2011, 5, 115-121, (In Korean).

16. International Organization for Standardization. Indoor Air-Part 23: Performance Test for Evaluating the Reduction of Formaldehyde Concentrations by Sorptive Building Materials; ISO/DIS 16000-23; International Organization for Standardization: Geneva, Switzerland, 2008.

17. International Organization for Standardization. Indoor Air-Part 24: Performance Test for Evaluating the Reduction of Volatile Organic Compounds and Carbonyl Compounds without Formaldehyde Concentrations by Sorptive Building Materials; ISO/DIS 16000-24; International Organization for Standardization: Geneva, Switzerland, 2008.

18. Japan Industrial Standard. Performance Test of Sorptive Building Materials of Reducing Indoor Air Pollution with Small Chamber - Part 1: Measurement of Adsorption Flux with Supplying Constant Concentration of Formaldehyde; JIS A 1905-1; Japanese Standard Association: Tokyo, Japan, 2007.

19. Japan Industrial Standard. Performance Test for Sorptive Building Materials of Reducing Indoor Air Pollution with Small Chamber-Part 2: Measurment of Capability for Suppressing Formaldehyde Emission; JIS A 1905-2; Japanese Standards Association: Tokyo, Japan, 2007.

20. Japan Industrial Standard. Performance Test of Sorptive Building Materials of Reducing Indoor Air Pollution with Small Chamber-Measurement of Adsorption Flux with Supplying Constant Concentration of Contaminant Air of VOC and Aldehydes without Formaldehyde; JIS A 1906; Japanese Standards Association: Tokyo, Japan, 2008.

21. Wolkoff, P. Photocopiers and indoor air pollution. Atmos. Environ. 2011, 33, 2029-2030. [CrossRef] 
22. Kim, S.; Drzal, L.T. High latent storage and high thermal conductive phase change materials using exfoliated graphite nanoplatelets. Sol. Energy Mater. Sol. Cells 2009, 93, 136-142. [CrossRef]

23. Lee, Y.K.; Kim, H.J. The effect of temperature on VOCs and carbonyl compounds emission from wooden flooring by thermal extractor test method. Build. Environ. 2012, 53, 95-99. [CrossRef]

(c) 2015 by the authors; licensee MDPI, Basel, Switzerland. This article is an open access article distributed under the terms and conditions of the Creative Commons by Attribution (CC-BY) license (http:/ / creativecommons.org/licenses/by/4.0/). 